includes safety gates, fireguards, window restrictors, cupboard locks, corner cushions and bathmats. The scheme is not just about equipment. Over 2 years it will provide 500000 families with information and support that will help them to create a safer environment. Safe At Home is also rolling out a comprehensive training programme for delivery partners who work with families, with over 3000 training places being offered throughout the scheme. A website a vital resource for both families and local schemes was launched in June. See http:// www.safeathome.rospa.com/. Other developments include a DVD with training notes and discussion points which is used as part of a facilitated session. An accompanying height chart, highlighting the key risks and prevention advice left with each family is a practical aid that backs up the information in the DVD. Working within 140 Local Authorities the scheme is an excellent example of multi-agency working. Independent evaluation will identify effectiveness and appropriateness. We will also be able to share the challenges and solutions in delivering such an extensive project.

\section{SAFE AT HOME - THE NATIONAL HOME SAFETY} EQUIPMENT SCHEME

S Merril*, E Taylor* Correspondence: The Royal Society for the Prevention of Accidents (RoSPA), RoSPA House, Edgbaston Park, 353 Bristol Road, Birmingham B5 7ST, UK

\subsection{6/ip.2010.029215.343}

Safe At Home (National Home Safety Equipment Scheme) is an 18 million initiative supported by the Department for Children Schools and Families. Its aim is to help families keep their children safe and to reduce accident rates in the home. Working with locally based delivery partners the scheme is providing home safety equipment to over 100000 of the most disadvantaged families in areas with the highest accident rates. The equipment which is provided with a fitting service 